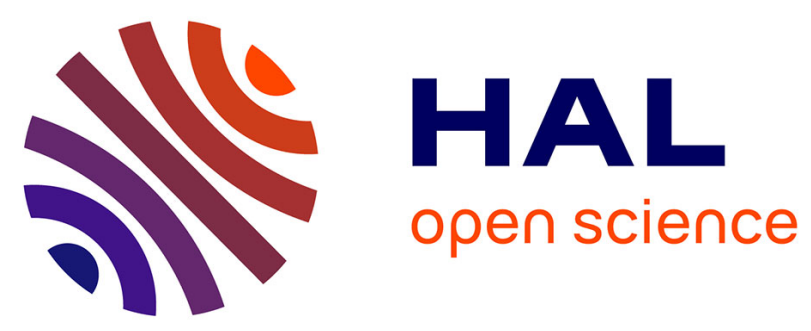

\title{
1-octanol, a self-inhibitor of spore germination in Penicillium camemberti
}

\author{
Guillaume Gillot, Nicolas Decourcelle, Gaëlle Dauer, Georges Barbier, \\ Emmanuel Coton, David Delmail, Jérôme Mounier
}

\section{- To cite this version:}

Guillaume Gillot, Nicolas Decourcelle, Gaëlle Dauer, Georges Barbier, Emmanuel Coton, et al.. 1octanol, a self-inhibitor of spore germination in Penicillium camemberti. Food Microbiology, 2016, 57, pp.1-7. 10.1016/j.fm.2015.12.008 . hal-01254795

\section{HAL Id: hal-01254795}

\section{https://hal-univ-rennes1.archives-ouvertes.fr/hal-01254795}

Submitted on 21 Apr 2016

HAL is a multi-disciplinary open access archive for the deposit and dissemination of scientific research documents, whether they are published or not. The documents may come from teaching and research institutions in France or abroad, or from public or private research centers.
L'archive ouverte pluridisciplinaire HAL, est destinée au dépôt et à la diffusion de documents scientifiques de niveau recherche, publiés ou non, émanant des établissements d'enseignement et de recherche français ou étrangers, des laboratoires publics ou privés. 


\section{1-octanol, a self-inhibitor of spore germination in Penicillium}

\section{2 camemberti}

3

4 Guillaume Gillot ${ }^{1}$, Nicolas Decourcelle ${ }^{2}$, Gaëlle Dauer ${ }^{2}$, Georges Barbier $^{1}$, Emmanuel Coton $^{1}$, $5 \quad$ David Delmail $^{3}$, Jérôme Mounier ${ }^{1 *}$.

6

$7{ }^{1}$ Université de Brest, EA 3882 Laboratoire Universitaire de Biodiversité et Ecologie 8 Microbienne, ESIAB, Technopôle Brest-Iroise, 29280 Plouzané, France.

$9{ }^{2}$ Université de Brest, EA 3882 Laboratoire Universitaire de Biodiversité et Ecologie 10 Microbienne, IUT de Quimper, 2, rue de l’Université 29200, Quimper, France

$11{ }^{3}$ Université de Rennes 1, UEB, UMR CNRS 6226 ISCR PNSCM, 2 avenue du Professeur 12 Léon Bernard, 35043 Rennes, France.

Running title: Quorum sensing in Penicillium camemberti

*Corresponding author: Jérôme Mounier

EA3882 - Laboratoire Universitaire de Biodiversité et Ecologie Microbienne,

Parvis Blaise Pascal, Technopôle Brest-Iroise

29280 Plouzané, France

Tel: +33 (0)2.90.91.51.10

Fax: $+33(0) 2.90 .91 .51 .01$

E-mail: jerome.mounier@univ-brest.fr 


\section{Abstract}

Penicillium camemberti is a technologically relevant fungus used to manufacture mouldripened cheeses. This fungal species produces many volatile organic compounds (VOCs) including ammonia, methyl-ketones, alcohols and esters. Although it is now well known that VOCs can act as signaling molecules, nothing is known about their involvement in $P$. camemberti lifecycle. In this study, spore germination was shown to be self-regulated by quorum sensing in P. camemberti. This phenomenon, also called the "crowding effect", is population-dependent (i.e. observed at high population densities). After determining the volatile nature of the compounds involved in this process, 1-octanol was identified as the main compound produced at high-spore density using GC-MS. Its inhibitory effect was confirmed in vitro and $3 \mathrm{mM}$ 1-octanol totally inhibited spore germination while $100 \mu \mathrm{M}$ only transiently inhibited spore germination. This is the first time that self-inhibition of spore germination is demonstrated in $P$. camemberti. The obtained results provide interesting perspectives for better control of mould-ripened cheese processes.

Keywords: Cheese, quorum sensing, Penicillium camemberti, germination, 1-octanol.

Chemical compounds studied in this article: 1-octanol (PubChem CID: 957), ethanol (PubChem CID: 702), ammonia (PubChem CID: 222), 2-heptanone (PubChem CID: 8051), 2-nonanone (PubChem CID: 13187), 1-octen-3-ol (PubChem CID: 18827), trans-2-octen-1-ol (PubChem CID: 5318599), 2-methyl-1-butanol (PubChem CID: 8723), 3-methyl-1-butanol (PubChem CID: 31260) and 3-octanone (PubChem CID: 246728). 


\section{Introduction}

Fungal spores can be dispersed in different ways, namely through air, dust or water, and are important for fungal dissemination and/or survival. Conidia are dispersed asexual spores and can be released in massive numbers by fungi, in particular by Penicillium genus members (Dijksterhuis and Samson, 2002) including many food-related species. While conidia are easily disseminated, spore germination only occurs when favorable environmental conditions (i.e. temperature, $\mathrm{pH}$, humidity, light and nutrients) are met. Spore germination is also influenced by spore density and is hindered at high spore densities (Macko et al., 1972). First evidence for this phenomenon, also called "quorum sensing", was shown for genetic competence induction (Felkner and Wyss, 1964; Tomasz and Hotchkiss, 1964) and in light production regulation (Nealson and Hastings, 1979) in Gram-positive bacteria and marine vibrios, respectively. The ability of microbial cells to chemically sense the density of the surrounding population (Fuqua et al., 1994) by extracellular factors has also been found in diverse microorganisms including fungi (Hogan, 2006). This phenomenon actually allows for cell density-dependent growth regulation, hence the term "crowding effect", and appears to be prevalent in diverse fungal species (Hogan, 2006). Previous studies suggested that intercellular signaling via self-inhibitor compound production prevents premature germination and guarantees that spores only germinate at the suitable time, i.e. in favorable environmental conditions.

Self-inhibitors, which can correspond or not to volatile compounds, have been characterized in numerous fungal genera including Aspergillus, Colletotrichum, Dictyostelium, Fusarium, Glomerella, Penicillium, Puccinia, Syncephalastrum and Uromyces (Bacon et al., 1973; Barrios-González et al., 1989; Chitarra et al., 2004; Garrett and Robinson, 1969; Hobot and Gull, 1980; Lax et al., 1985; Leite and Nicholson, 1992; Lingappa et al., 1973; Macko et al., 1972). Regarding the Penicillium genus, Chitarra et al. (2004, 2005) demonstrated that 1- 
octen-3-ol influenced different developmental processes during the Penicillium paneum lifecycle, including spore germination inhibition.

Penicillium camemberti, first described by Thom in 1906 (Raper and Thom, 1949), is mainly used in cheese manufacture and more particularly for mould-ripened soft cheeses such as Camembert, Brie and Coulommiers. P. camemberti growth results in the formation of a characteristic white rind (Abbas and Dobson, 2011). During spore germination and mycelial growth, lipase and protease activities are involved in lipid and protein degradation in cheese resulting in fatty and amino acid release (Beresford and Williams, 2004). These latter are then transformed into important taste and aroma compounds such as ammonia, methyl-ketones, primary and secondary alcohols, esters, aldehydes, lactones and sulfur compounds (Abbas and Dobson, 2011) and contribute to overall organoleptic qualities.

Due to the important role of $P$. camemberti in cheese manufacture, there is a clear interest to understand regulatory mechanisms potentially involved in conidia germination to better control soft mould-ripened cheese production. In this context, the aims of this study were to first investigate the effect of spore density on spore germination in P. camemberti, then to identify the molecules involved and finally estimate the impact of the identified compound and other volatile compounds on spore germination.

\section{Materials and methods}

\subsection{Strains, culture conditions and spore suspension preparations}

Two commercial P. camemberti strains (coded P. camemberti A and B for confidentiality reasons) isolated from mould-ripened cheeses and P. camemberti UBOCC-A-101392 and UBOCC-A-108097, and CBS $299.48^{\mathrm{T}}$ respectively obtained from the Université de Bretagne Occidentale Culture Collection (UBOCC, Plouzané, France) and the Central Bureau Voor Schimmelcultures (Baarn, Netherlands) were used in this study. Pre-cultures were prepared 
on slant Potato Dextrose Agar (Difco PDA, Becton, Dickinson and Company, Franklin Lakes, NJ, USA) by inoculating a spore suspension, conserved at $-80^{\circ} \mathrm{C}$ in $10 \%$ glycerol $(\mathrm{v} / \mathrm{v})$, and incubating tubes for 7 days at $25^{\circ} \mathrm{C}$. Strains were then sub-cultured on slant PDA and incubated at $25^{\circ} \mathrm{C}$ for 14 days. After incubation, spores were harvested using $8 \mathrm{~mL}$ of sterile distilled water supplemented with $0.1 \%$ Tween 80 . Slant agar cultures were scraped using a 1 $\mathrm{mL}$ sterile pipette to collect spores. Then, Roux flasks containing $100 \mathrm{~mL}$ Malt Extract Agar (MEA, Merck, Darmstadt, Germany) were sowed with $6 \mathrm{~mL}$ spore suspension. After incubation for 14 days at $25^{\circ} \mathrm{C}, 25 \mathrm{~mL}$ of sterile distilled water supplemented with $0.1 \%$ Tween 80 were added to each Roux flask and the mycelium surface was scraped using a cell scraper (Becton, Dickinson and Company, Franklin Lakes, NJ, USA). The resulting spore suspension was transferred into a tube and centrifuged for $5 \mathrm{~min}$ at $4000 \mathrm{~g}$ at $4^{\circ} \mathrm{C}(\mathrm{CR} 3 \mathrm{i}$ multifunction, Thermo Fisher Scientific Inc., Waltham, MA, USA). After carefully discarding the supernatant, spores were resuspended in $5 \mathrm{~mL}$ sterile distilled water supplemented with $0.1 \%$ of Tween 80 . Finally, all suspensions of a same strain were pooled together, counted using a Malassez cell and standardized to $2.10^{8}$ and $2.10^{6}$ spores.mL $\mathrm{m}^{-1}$.

\subsection{Effect of spore concentration on germination kinetics in culture broth}

Spore germination kinetics were performed as described by Chitarra et al. (2004, 2005) with some modifications in Malt Extract Broth (MEB, Merck, Darmstadt, Germany) using fresh spore suspensions. To determine the effect of spore density on germination kinetics, $0.75 \mathrm{~mL}$ spore suspensions (either $2.10^{8}$ or $2.10^{6}$ spores.mL ${ }^{-1}$ ) were mixed with $0.75 \mathrm{~mL} \mathrm{MEB} 2 \mathrm{X}$ to obtain a final spore concentration of $10^{8}$ or $10^{6}$ spores. $\mathrm{mL}^{-1}$. Suspensions were then incubated horizontally in a rotary shaker set to $25^{\circ} \mathrm{C}$ and $120 \mathrm{rpm}$. Germination was followed at $0 \mathrm{~h}, 8 \mathrm{~h}$, then at $2 \mathrm{~h}$ intervals for the following $12 \mathrm{~h}$. A minimum of 100 conidia were counted to determine germination kinetics (i.e. percentage of germinated spore as a function of time). A 
spore was considered as germinated when the germinal tube length was superior or equal to the spore diameter itself, as previously described (Dantigny et al., 2006). In addition, in order to examine whether spore germination capacity was related to spore density, high density spore suspensions obtained after $20 \mathrm{~h}$ incubation were diluted to $10^{6}$ spores. $\mathrm{mL}^{-1}$ in fresh MEB 1X and incubated for another $18 \mathrm{~h}$. Moreover, to assess whether inhibitory molecules were produced during incubation at high spore density, filter sterilized cultures obtained after $20 \mathrm{~h}$ incubation were inoculated at $10^{6}$ spores. $\mathrm{mL}^{-1}$ and also incubated for another $18 \mathrm{~h}$. For each spore concentration level, three technical replicates and two biological replicates were performed.

\subsection{Effect of spore density on spore germination and radial growth in agar medium}

In these experiments, a Petri dish containing Malt Extract Agar (MEA, Merck, Darmstadt, Germany) layers at the bottom and the top (in the lid) was used as described previously (Chitarra et al., 2004). The top MEA layer was surface inoculated with $50 \mu \mathrm{L}$ of a $10^{6}$ or $10^{8}$ spores. $\mathrm{mL}^{-1}$ suspension while $5 \mu \mathrm{L}$ of a $10^{7}$ spores. $\mathrm{mL}^{-1}$ suspension were deposited into the center of the plate on the bottom layer. Control cultures were also performed without inoculating the top layer. Colony diameters were measured in two perpendicular directions every 2 days for 14 days (plates were incubated at $25^{\circ} \mathrm{C}$ ). Five replicates per condition were performed. Mean values $\pm 95 \%$ confidence intervals were calculated for each condition.

\subsection{Extraction of volatile compounds}

Volatile compounds produced by $P$. camemberti in liquid cultures after $20 \mathrm{~h}$ incubation were extracted as previously described (Husson et al., 2002). Briefly, $0.5 \mathrm{~g} \mathrm{NaCl}$ and $1 \mathrm{~mL}$ diethyl ether were added to $1 \mathrm{~mL}$ culture suspension followed by centrifugation at 15,000 $\mathrm{g}$ for $2 \mathrm{~min}$ 
at room temperature. The organic phase (superior phase) was recuperated and $\mathrm{Na}_{2} \mathrm{SO}_{4}$ was added to remove any traces of water.

\subsection{Detection and identification of volatile compound(s) by GC-MS}

Detection and identification of volatile compounds were performed by gas chromatography (Agilent Technologies 7820A GC Systems, Agilent Technologies, Santa Clara, CA, USA) coupled with mass spectrometry (Agilent Technologies 5975 Series MSD, Agilent Technologies, Santa Clara, CA, USA) using a HP-5ms (30 m x $250 \mu \mathrm{m}$ x $0.25 \mu \mathrm{m})$ column. The program used for the oven was as follows: $50^{\circ} \mathrm{C}$ for $5 \mathrm{~min}, 4^{\circ} \mathrm{C} \cdot \mathrm{min}^{-1}$ between $50^{\circ} \mathrm{C}$ and $200^{\circ} \mathrm{C}$ then $10^{\circ} \mathrm{C} \cdot \mathrm{min}^{-1}$ from $200^{\circ} \mathrm{C}$ to $270^{\circ} \mathrm{C}$, followed by a final step at $270^{\circ} \mathrm{C}$ for $10 \mathrm{~min}$. The injector and detector temperatures were set to $250^{\circ} \mathrm{C}$ and $300^{\circ} \mathrm{C}$, respectively. The conditions of the mass spectrometer were mode electronic impact (EI); temperature source $250^{\circ} \mathrm{C}$; scanning speed 1 scan.s $\mathrm{s}^{-1}$; mass acquisition 50-300 uma. The vector gas was $\mathrm{H}_{2}$ at a

$1.5 \mathrm{~mL} \cdot \mathrm{min}^{-1}$ flow rate. For identification, mass spectra were compared to the NIST mass spectral library and were confirmed using the retention index and mass spectrum of pure compounds.

\subsection{Effect of pure volatile compounds on spore germination in MEB medium}

The impact of the major volatile compound identified by GC-MS on the spore germination process was evaluated in MEB for two strains (P. camemberti A and B) at concentrations ranging between 0 and $4 \mathrm{mM}$. The effect of other volatile compounds potentially produced by P. camemberti, i.e. ethanol, ammonia, 2-heptanone, 2-nonanone, 1-octen-3-ol, trans-2-octen1-ol, 2-methyl-1-butanol, 3-methyl-1-butanol and 3-octanone, was also investigated. To perform these assays, after solubilization of the tested compound in propylene glycol and serial dilutions, the percentage of germinated conidia from a $10^{6}$ spore. $\mathrm{mL}^{-1}$ suspension was 
determined in MEB as described above, after 10 and $16 \mathrm{~h}$ incubation at $25^{\circ} \mathrm{C}$ with agitation (120 rpm). Control cultures without volatile compound but containing the same amount of propylene glycol were also performed.

\subsection{Effect of initial spore concentration on the growth of $P$. camemberti determined by}

\section{ergosterol analysis in a cheese matrix model}

The cheese matrix model was prepared as described previously (Le Dréan et al., 2010). Briefly, to prepare $100 \mathrm{~g}, 23 \mathrm{~g}$ milk protein concentrate, $20 \mathrm{~g}$ anhydrous milk fat, $50 \mathrm{~mL}$ sterile distilled water, $1.5 \mathrm{~g} \mathrm{NaCl}$ and $1.26 \mathrm{~mL}$ lactic acid were added. Prepared model cheeses were inoculated with either P. camemberti A or B spore suspensions to yield a final spore concentration ranging from $10^{2}$ to $10^{6}$ spores. $\mathrm{g}^{-1}$. Then, $50 \mathrm{~g}$ cheese portions were transferred to sterile crystallizing dishes $\left(5.6-\mathrm{cm}\right.$ diameter) and incubated for 9 days at $12^{\circ} \mathrm{C}$. After incubation, a 32- $\mathrm{mm}$ diameter and $\sim 5 \mathrm{~mm}$ depth layer was removed from the cheese surface with a sterile scalpel. Sufficient sterile $2 \%(\mathrm{w} / \mathrm{v})$ trisodium citrate was added to yield a 1:10 dilution and the resulting suspension was homogenized with an Ultra-Turrax (IKA, Staufen, Germany) at $24,000 \mathrm{rpm} \cdot \mathrm{min}^{-1}$ for $1 \mathrm{~min}$. Five $\mathrm{mL}$ of the trisodium citrate / cheese mixture were then centrifuged in a $12-\mathrm{mL}$ screw cap tube at $10,000 \mathrm{~g}$ for $10 \mathrm{~min}$ at $4^{\circ} \mathrm{C}$. The supernatant was discarded and the mycelium pellets resuspended in $0.5 \mathrm{~mL}$ of methanol. After vortexing, $2.5 \mathrm{~mL}$ of $24 \%$ methanolic $\mathrm{KOH}(24 \%)$ were added and incubated for $2 \mathrm{~h}$ at $85^{\circ} \mathrm{C}$. After cooling in melted ice for $10 \mathrm{~min}, 2 \mathrm{~mL}$ of petroleum ether were added and vortexed 3 times for $20 \mathrm{sec}$ with a cooling step on ice for 2 min after each homogenization treatment. This step was repeated and the extract was centrifuged for 10 min at $3000 \mathrm{rpm}$ at $4^{\circ} \mathrm{C}$. The organic phase was collected and evaporated under nitrogen flow for $\sim 15$ min and stored at $-20^{\circ} \mathrm{C}$ before use. Prior to HPLC analysis, the dry extract was dissolved in $0.5 \mathrm{~mL}$ methanol and filtered through a $0.45-\mu \mathrm{m}$ acetate filter. Ergosterol was quantified, using 
external ergosterol standards (Sigma, St Louis, MO, USA), with a high-performance liquid chromatograph Agilent 1100 series (Agilent Technologies, Santa Clara, CA, USA) equipped with an Interchrom Lichrospher C18 column and an UV detector set at $282 \mathrm{~nm}$. The mobile phase was methanol with a flow rate set to $1.2 \mathrm{~mL} \cdot \mathrm{min}^{-1}$ and injection volume was $50 \mu 1$. Each sample and standard were analyzed in triplicate. Mean values $\pm 95 \%$ confidence intervals were calculated for each strain and condition.

\section{Results}

\subsection{Effect of spore concentration on germination kinetics in broth medium}

Germination kinetics according to initial spore population for the 2 studied P. camemberti strains in MEB are presented in Fig. 1. Independently of the studied strains, cultures containing $10^{6}$ spores. $\mathrm{mL}^{-1}$ presented higher germination percentages compared to $10^{8}$ spores. $\mathrm{mL}^{-1}$ cultures. Indeed, after $20 \mathrm{~h}$ incubation, $>90 \%$ and $<3 \%$ spores had germinated at $10^{6}$ versus $10^{8}$ spores. $\mathrm{mL}^{-1}$. Similar results were also obtained on $P$. camemberti strains UBOCC-A-101392, UBOCC-A-108097 and CBS 299.48 (data not shown). To determine whether germination inhibition was the consequence of higher spore density, $10^{8}$ spores. $\mathrm{mL}^{-1}$ cultures obtained after $20 \mathrm{~h}$ incubation were diluted to $10^{6}$ spores. $\mathrm{mL}^{-1}$ and further incubated for $18 \mathrm{~h}$. Germination percentages for both strains were $~ 90 \%$ indicating that a "crowdingeffect" was responsible for this inhibition.

In order to check for self-inhibitory molecules in the high density spore suspension, $20-\mathrm{h} 10^{8}$ spores. $\mathrm{mL}^{-1}$ culture filtrates were inoculated with a new spore suspension $\left(10^{6}\right.$ spores. $\left.\mathrm{mL}^{-1}\right)$ and germination kinetics were compared to a control (Fig. 2). While $98 \%$ of spores had germinated in the control, germination rates in the culture filtrates were only $13 \%$ and $8 \%$ for P. camemberti A and B, respectively (Fig. 2), thus, highlighting that one or several selfinhibitors were present in the culture medium previously containing $10^{8}$ spores. $\mathrm{mL}^{-1}$. 
To examine if spore density could impact spore germination and radial growth in solid

226

227 medium, a Petri dish containing MEA layers at both the bottom and top (in the lid) was used as previously described by Chitarra et al. (2004, 2005). As shown in Fig. 3, growth in the bottom of the Petri dish was significantly delayed as compared to the control (Fig. 3A) when the lid was inoculated with $50 \mu \mathrm{L}$ of a spore suspension containing $10^{6}$ (Fig. 3B) or $10^{8}$ (Fig. 3C) spores. $\mathrm{mL}^{-1}$, the latter having the strongest effect. Indeed, mean radial growth rates were 4.14, 0.57 and $0.47 \mathrm{~mm} \cdot \mathrm{d}^{-1}$ for the control and the lid agar inoculated with $10^{6}$ and $10^{8}$ spores. $\mathrm{mL}^{-1}$, respectively. Overall, these results strongly suggested that volatile compounds, able to move from the MEA layer of production to the MEA layer of action, could be responsible for the observed effects.

\subsection{Detection and identification of volatiles compound(s) by GC-MS}

The volatile compounds present in MEB cultures containing $10^{8}$ spores.mL $L^{-1}$ of $P$. camemberti strain A or B were analyzed by GC/MS and compared to those of the noninoculated MEB medium (Fig. 4). Major differences in volatile compound profiles between the inoculated media (Fig. 4A) and control (Fig. 4B) were observed. Noteworthy, the most abundant volatile compound produced at high spore density exhibited a retention time of $10.997 \mathrm{~min}$. The nature of this compound was assigned to 1-octanol based on its mass spectrum (Fig. 4C) and confirmed after comparison of its mass spectrum with that of pure 1octanol (Fig. 4D). This compound was also verified to have a different retention time and mass spectrum from those of 1-octen-3-one, 3-octanone, 2-octanone, octanal, trans-2-octen-1ol and 1-octen-3-ol (retention times were 7.237, 8.03, 8.201, 8.488, 11.935 and 12.796 min, respectively) in the tested conditions (data not shown). 


\subsection{Effect of pure volatile compounds on germination efficiency in MEB}

The effects of 1-octanol, as well as other volatile compounds potentially produced by $P$. camemberti, on germination efficiency were studied in vitro. The germination inhibitory effect of 1-octanol was confirmed in MEB. Indeed, total inhibition of spore germination was achieved in the presence of $3 \mathrm{mM}$ 1-octanol while a concentration as low as $100 \mu \mathrm{M}$ transiently delayed spore germination after $10 \mathrm{~h}$ but not after $16 \mathrm{~h}$. Indeed, at the latter concentration, the percentage of germinated spores was reduced by $10 \%$ as compared to the control. It is worth mentioning that 1-octen-3-ol, a compound previously identified to act as a self-inhibitor in P. paneum (Chitarra et al., 2005, 2004), and its isomer trans-2-octen-1-ol had a similar minimum inhibitory concentration (MIC) than 1-octanol. Other compounds, namely, ethanol, ammonia, 2-methyl-1-butanol, 3-methyl-1-butanol, 2-heptanone and 3-octanone did not inhibit spore germination in the tested conditions (MIC $>4 \mathrm{mM})$.

\subsection{Effect of spore concentration on $P$. camemberti growth as determined by} ergosterol analysis in a cheese matrix model

Fungal biomass obtained after 9 days incubation at $12{ }^{\circ} \mathrm{C}$ as a function of the initial spore concentration $\left(10^{2}\right.$ to $10^{6}$ spores. $\mathrm{g}^{-1}$ of cheese $)$ is shown in Fig. 5. Independently of the tested strain, there was no significant difference in fungal biomass whatever the initial spore concentration used.

\section{Discussion}

270 Self-regulation of spore germination as a function of spore density has been previsouly 271 characterized in a wide range of fungal species including Penicillium species (Chitarra et al., 2004, 2005). In the present study, we demonstrated for the first time that this phenomenon, 
which was reversible, also occurred in P. camemberti, an industrially relevant fungus used in the dairy industry. We also showed that 1-octanol, a volatile compound, was produced at high spore density and that this compound hindered spore germination in vitro. In nature, Penicillium spp. produce high spore numbers which are directly exposed to air, thus explaining why volatile self-inhibitors may be more widespread than non-volatile ones. Thus, as suggested by Chitarra et al. (2004) for 1-octen-3-ol, we can hypothesize that 1-octanol is produced by $P$. camemberti conidia and released into the air in order to inhibit germination until appropriate environmental conditions are met. Likewise, as previously described for 1octen-3-ol in P. paneum and Aspergillus nidulans (Chitarra et al., 2005; Herrero-Garcia et al., 2011), conidia treated with 3 and $4 \mathrm{mM}$ 1-octanol did not enter into isotropic growth, meaning that 1-octanol prevented the initiation of the spore swelling process which precedes polarized growth and the formation of a germ tube. Thus, this volatile compound may have an effect on fungal membrane permeabilisation which controls water entry into conidia (Chitarra et al., 2005).

More generally, eight-carbon (8-C) volatiles are ubiquitous among fungi and characteristic of fungal aromas (Combet et al., 2006). They result from the oxidation and cleavage of fatty acids, in particular linoleic acid. Such products constitute for 44.3-97.6\% of the total amount of volatiles produced, depending on the extraction method used (Maga, 1981; Tressl et al., 1982; Venkateshwarlu et al., 1999). The well-known 1-octen-3-ol presenting a mushroomlike aroma is the most abundant VOC while 1-octanol is characterized by a detergent, soap and orange-like aroma (Combet et al., 2006). In the present study, 1-octanol was the only 8-C volatile compound identified in cultures with high conidial density while 1-octen-3-ol was not detected. Likewise, P. commune, which is considered as an ancestral form of the domesticated P. camemberti (Pitt et al., 1986), was not found to produce 1-octen-3-ol at high spore density (Chitarra et al., 2005). Nevertheless, 1-octen-3-ol was found, here, to block the germination 
process in vitro. Given that the role of this compound as a self-inhibitor of germination has also been demonstrated in several fungal genera and species (Chitarra et al., 2004; HerreroGarcia et al., 2011), it could be considered as a cross-talk molecule. In addition, 1-octen-3-ol is produced at high levels by P. camemberti during growth, especially in cheese (Abbas and Dobson, 2011), therefore its role in controlling other steps of the P. camemberti growth cycle cannot be excluded and should be further studied. Finally, 3-octanone, a methyl-ketone derived from linoleic acid which is also produced by P. camemberti (Adda et al., 1989), also deserves further attention since this compound was identified as a conidiogenic compound in A. nidulans (Herrero-Garcia et al., 2011).

In the last part of the present study, we investigated whether the initial spore inoculum could impact the $P$. camemberti colonization process in model cheeses. We found that estimated biomass by ergosterol measurements was similar regardless of initial inoculum, suggesting that the germination and growth coordination phenomena could also occur in cheese. In addition, low inoculum levels containing $10^{2}-10^{3}$ spores. $\mathrm{g}^{-1}$ of cheese could be sufficient to maximize $P$. camemberti growth. In the cheese industry, the inoculation level of $P$. camemberti is empirically determined as a function of the organoleptic properties desired in final product (surface appearance, texture and flavor). Better knowledge of the phenomena governing the $P$. camemberti colonization process could be useful to better control growth and metabolic activities during cheese ripening.

\section{Conclusions}

In the present study, self-regulation of spore germination by quorum sensing in P. camemberti was shown. The volatile nature of the involved compounds was demonstrated and 1-octanol was found to be the main volatile compound produced at high spore density. Its inhibitory effect was verified in vitro, showing that $3 \mathrm{mM}$ 1-octanol totally inhibited spore germination 
while $100 \mu \mathrm{M}$ only transiently inhibited this process. This is the first time that spore germination self-inhibition is detected in P. camemberti and such knowledge could be useful to better control the ripening process of mould-ripened cheeses.

\section{Acknowledgements}

The authors are thankful to CBB développement and the Région Bretagne for their financial support. We thank Danielle Arzur for technical assistance and Doctor Monika Coton for English revision.

\section{References}

Abbas, A., Dobson, A.D.W., 2011. Yeasts and Molds: Penicillium camemberti, in: Fuquay, J.W. (Ed.), Encyclopedia of Dairy Sciences. Academic Press, San Diego, pp. 776-779.

Adda, J., Dekimpe, J., Vassal, L., Spinnler, H.E., 1989. Production de styrène par Penicillium camemberti Thom. Le Lait 69, 115-120. doi:10.1051/lait:198928

Bacon, C.W., Sussman, A.S., Paul, A.G., 1973. Identification of a self-inhibitor from spores of Dictyostelium discoideum. J. Bacteriol. 113, 1061-1063.

Barrios-González, J., Martínez, C., Aguilera, A., Raimbault, M., 1989. Germination of concentrated suspensions of spores from Aspergillus niger. Biotechnol. Lett. 11, 551554. doi:10.1007/BF01040034

Beresford, T., Williams, A., 2004. The microbiology of cheese ripening, in: Fox, P.F., McSweeney, P.L.H., Cogan, T.M., Guinee, T.P. (Eds.), Cheese: Chemistry, Physics and Microbiology. Elsevier Academic Press, London, pp. 287-317.

Chitarra, G.S., Abee, T., Rombouts, F.M., Dijksterhuis, J., 2005. 1-Octen-3-ol inhibits conidia germination of Penicillium paneum despite of mild effects on membrane permeability, respiration, intracellular $\mathrm{pH}$, and changes the protein composition. FEMS Microbiol. Ecol. 54, 67-75. doi:10.1016/j.femsec.2005.02.013

Chitarra, G.S., Abee, T., Rombouts, F.M., Posthumus, M.A., Dijksterhuis, J., 2004. Germination of Penicillium paneum conidia is regulated by 1-Octen-3-ol, a volatile self-inhibitor. Appl. Environ. Microbiol. 70, 2823-2829. doi:10.1128/AEM.70.5.2823-2829.2004

Combet, E., Eastwood, D.C., Burton, K.S., Combet, E., Henderson, J., Henderson, J., Combet, E., 2006. Eight-carbon volatiles in mushrooms and fungi: properties, analysis, and biosynthesis. Mycoscience 47, 317-326. doi:10.1007/S10267-006-03184

Dantigny, P., Bensoussan, M., Vasseur, V., Lebrihi, A., Buchet, C., Ismaili-Alaoui, M., Devlieghere, F., Roussos, S., 2006. Standardisation of methods for assessing mould 
germination: a workshop report. Int. J. Food Microbiol. 108, 286-291. doi:10.1016/j.ijfoodmicro.2005.12.005

Dijksterhuis, J., Samson, R.A., 2002. Food and crop spoilage on storage, in: Kempken, P.D.F. (Ed.), Agricultural Applications, The Mycota. Springer Berlin Heidelberg, pp. 39-52.

Felkner, I.C., Wyss, O., 1964. A substance produced by competent Bacillus cereus 569 cells that affects transformability. Biochem. Biophys. Res. Commun. 16, 94-99. doi:10.1016/0006-291X(64)90217-7

Fuqua, W.C., Winans, S.C., Greenberg, E.P., 1994. Quorum sensing in bacteria: the LuxRLuxI family of cell density-responsive transcriptional regulators. J. Bacteriol. 176, 269-275.

Garrett, M.K., Robinson, P.M., 1969. A stable inhibitor of spore germination produced by fungi. Arch. Für Mikrobiol. 67, 370-377. doi:10.1007/BF00412583

Herrero-Garcia, E., Garzia, A., Cordobés, S., Espeso, E.A., Ugalde, U., 2011. 8-Carbon oxylipins inhibit germination and growth, and stimulate aerial conidiation in Aspergillus nidulans. Fungal Biol. 115, 393-400. doi:10.1016/j.funbio.2011.02.005

Hobot, J.A., Gull, K., 1980. The identification of a self-inhibitor from Syncephalastrum racemosum and its effect upon sporangiospore germination. Antonie Van Leeuwenhoek 46, 435-441.

Hogan, D.A., 2006. Talking to themselves: autoregulation and quorum sensing in fungi. Eukaryot. Cell 5, 613-619. doi:10.1128/EC.5.4.613-619.2006

Husson, F., Thomas, M., Kermasha, S., Belin, J.-M., 2002. Effect of linoleic acid induction on the production of 1-octen-3-ol by the lipoxygenase and hydroperoxide lyase activities of Penicillium camemberti. J. Mol. Catal. B Enzym., Proceedings of the 5th. International Symposium on Biocatalysis and Biotransformations 19-20, 363-369. doi:10.1016/S1381-1177(02)00187-X

Lax, A.R., Templeton, G.E., Meyer, W.L., 1985. Isolation, purification, and biological activity of a self-inhibitor from conidia of Colletotrichum gloeosporioides. Phytopathol. Biochem.

Le Dréan, G., Mounier, J., Vasseur, V., Arzur, D., Habrylo, O., Barbier, G., 2010. Quantification of Penicillium camemberti and P. roqueforti mycelium by real-time PCR to assess their growth dynamics during ripening cheese. Int. J. Food Microbiol. 138, 100-107. doi:10.1016/j.ijfoodmicro.2009.12.013

Leite, B., Nicholson, R.L., 1992. Mycosporine-alanine: A self-inhibitor of germination from the conidial mucilage of Colletotrichum graminicola. Exp. Mycol. 16, 76-86. doi:10.1016/0147-5975(92)90043-Q

Lingappa, B.T., Lingappa, Y., Bell, E., 1973. A self-inhibitor of protein synthesis in the conidia of Glomerella cingulata. Arch. Für Mikrobiol. 94, 97-107. doi:10.1007/BF00416685

Macko, V., Staples, R.C., Renwick, J.A.A., Pirone, J., 1972. Germination self-inhibitors of rust uredospores. Physiol. Plant Pathol. 2, 347-355. doi:10.1016/00484059(72)90060-4

Maga, J.A., 1981. Mushroom flavor. J. Agric. Food Chem. 29, 1-4. doi:10.1021/jf00103a001

Nealson, K.H., Hastings, J.W., 1979. Bacterial bioluminescence: its control and ecological significance. Microbiol. Rev. 43, 496-518.

Raper, K.B., Thom, C., 1949. A manual of the Penicillia. Williams and Wilkens Co., Baltimore.

Tomasz, A., Hotchkiss, R.D., 1964. Regulation of the transformability of pneumococcal cultures by macromolecular cell products. Proc. Natl. Acad. Sci. U. S. A. 51, 480-487. 
Tressl, R., Bahri, D., Engel, K.H., 1982. Formation of eight-carbon and ten-carbon components in mushrooms (Agaricus campestris). J. Agric. Food Chem. 30, 89-93. doi:10.1021/jf00109a019

Venkateshwarlu, G., Chandravadana, M.V., Tewari, R.P., 1999. Volatile flavour components of some edible mushrooms (Basidiomycetes). Flavour Fragr. J. 14, 191-194. doi:10.1002/(SICI)1099-1026(199905/06)14:3<191::AID-FFJ810>3.0.CO;2-7 
Figure legends

417 Fig. 1. Germination of Penicillium camemberti strain A (A) and B (B) conidia at $25^{\circ} \mathrm{C}$ in malt

418 extract broth as a function of the tested spore density $\left(10^{6}\right.$ spores.mL $L^{-1}$, and $10^{8}$ spores. $\mathrm{mL}^{-1}$,

$419 \boldsymbol{\Delta})$. The arrows represent the time (20h) at which the spore suspensions were diluted to $10^{6}$ spores. $\mathrm{mL}^{-1}$. Two biological replicates and three technical replicates were performed for each strain. Error bars represent standard deviations.

Fig. 2. Germination kinetics (inoculum level of $10^{6}$ spores.mL ${ }^{-1}$ ) of Penicillium camemberti

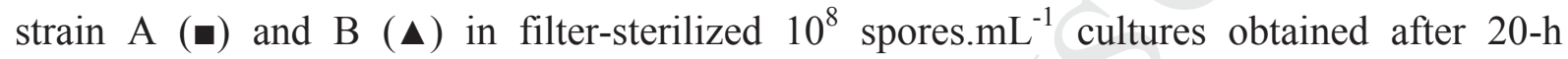
incubation (doted lines) as compared to germination of strain A ( $\mathbf{\square})$ and B ( $\mathbf{\Delta})$ in fresh malt extract broth (solid lines). Error bars represent standard deviations.

Fig. 3. Inhibition of spore germination and radial growth of Penicillium camemberti cultivated on malt extract agar in the absence (A) or in the presence of a $50 \mu \mathrm{L}$ at $10^{6}$ (B) or $10^{8}$ (C) spores. $\mathrm{mL}^{-1}$ inoculated in the top layer (in the lid) of a Petri dish. CI95\%: 95\% confidence interval.

Fig. 4. Chromatograms showing the volatile compounds found in malt extract broth containing $10^{8}$ spores. $\mathrm{mL}^{-1}$ of Penicillium camemberti strain A after $20 \mathrm{~h}$ incubation at $25^{\circ} \mathrm{C}$ (A) in comparison with non-inoculated MEB (B) and the mass spectra of the molecule presenting a retention time of $10.997 \mathrm{~min}(\mathrm{C})$ in comparison with pure 1-octanol (D).

Fig. 5. Fungal biomass (mean $\pm 95 \%$ confidence interval) of Penicillium camemberti strain A (black bars) and $\mathrm{B}$ (grey bars) after 9 days incubation at $12^{\circ} \mathrm{C}$ in a cheese matrix model as a

440 function of initial spore concentration ranging from $10^{2}$ to $10^{6}$ spores. $\mathrm{g}^{-1}$ cheese. 
441

$442 \quad$ Fig. 1.

443 A

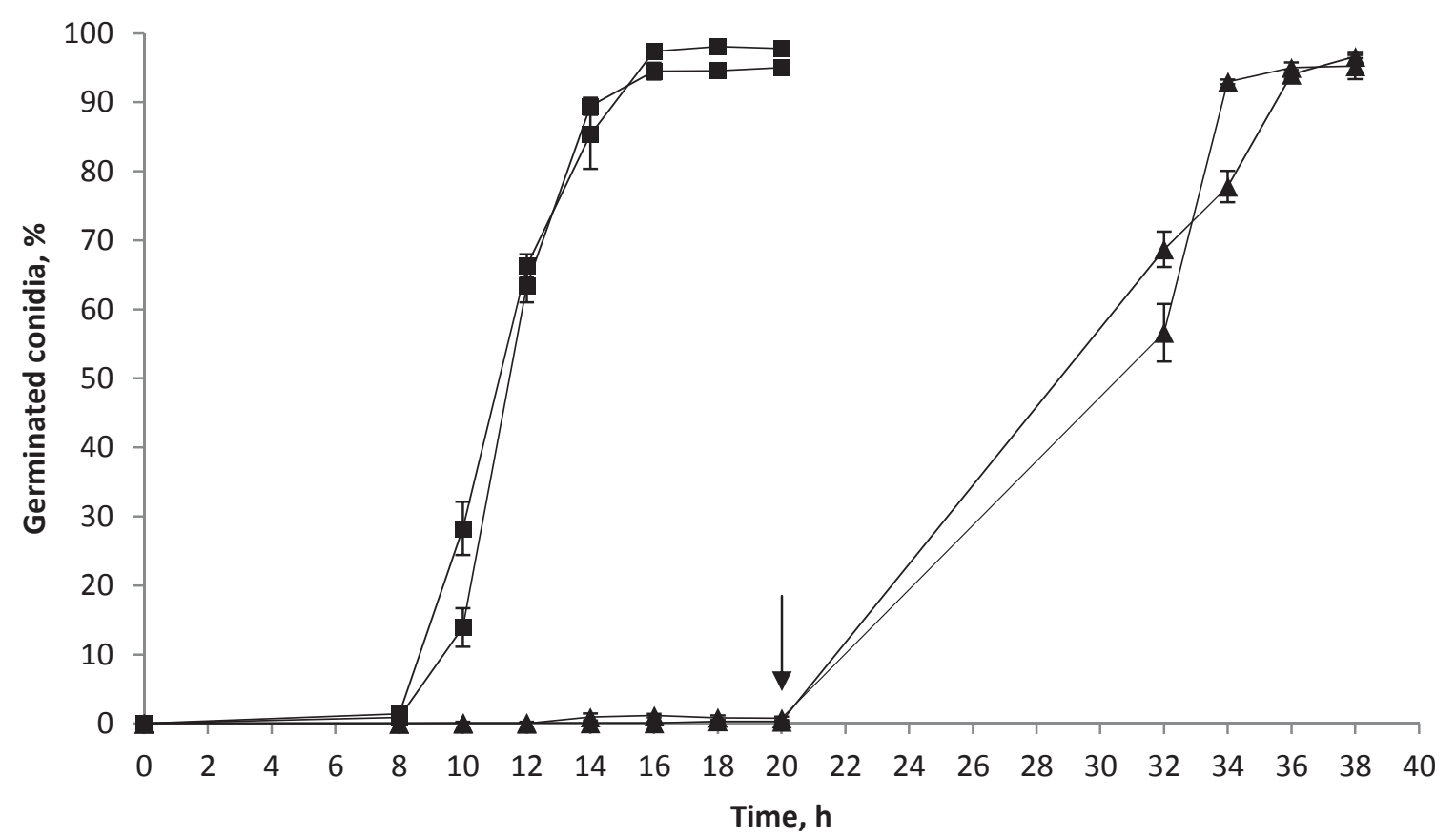

444

445

B

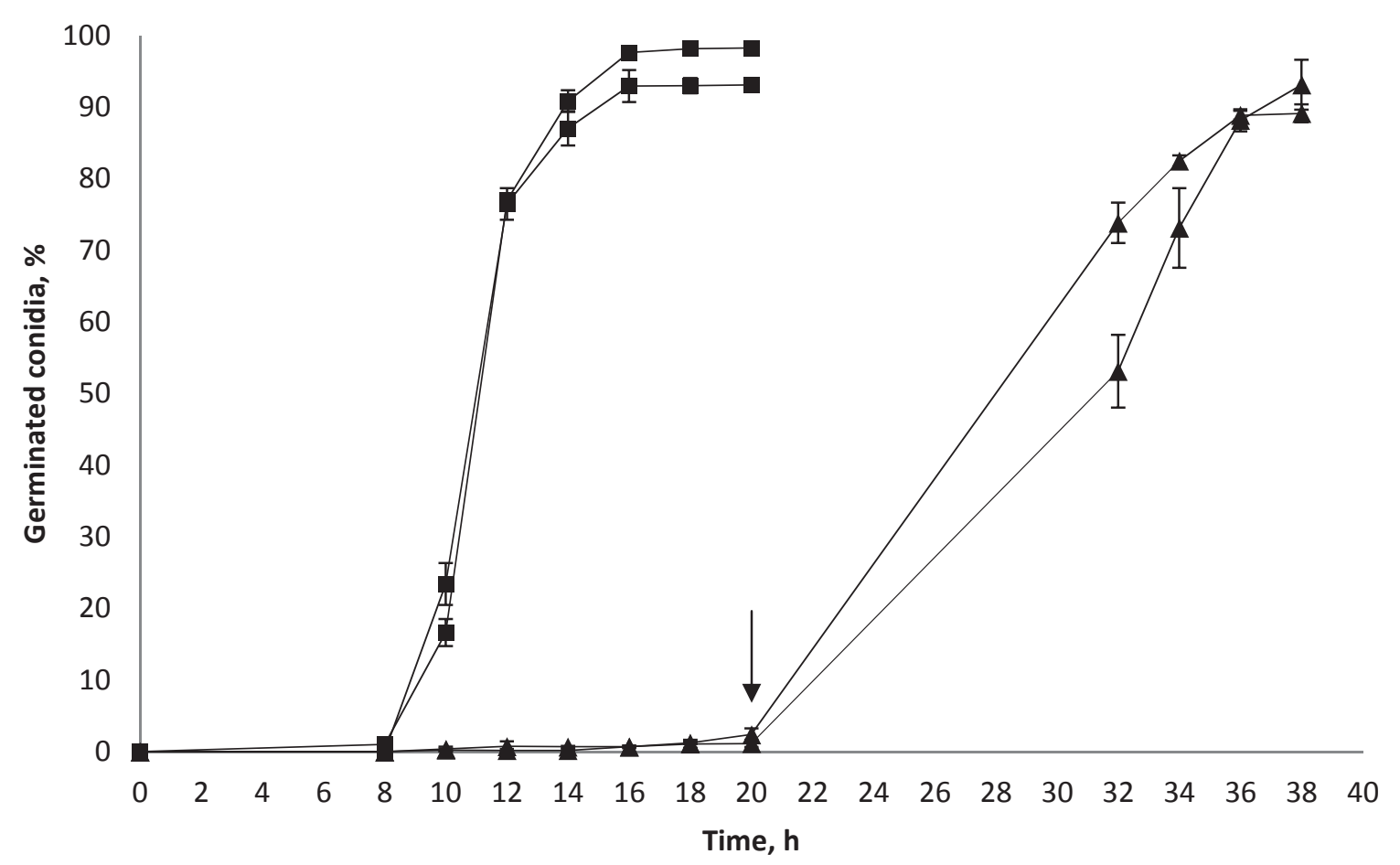


$448 \quad$ Fig. 2.

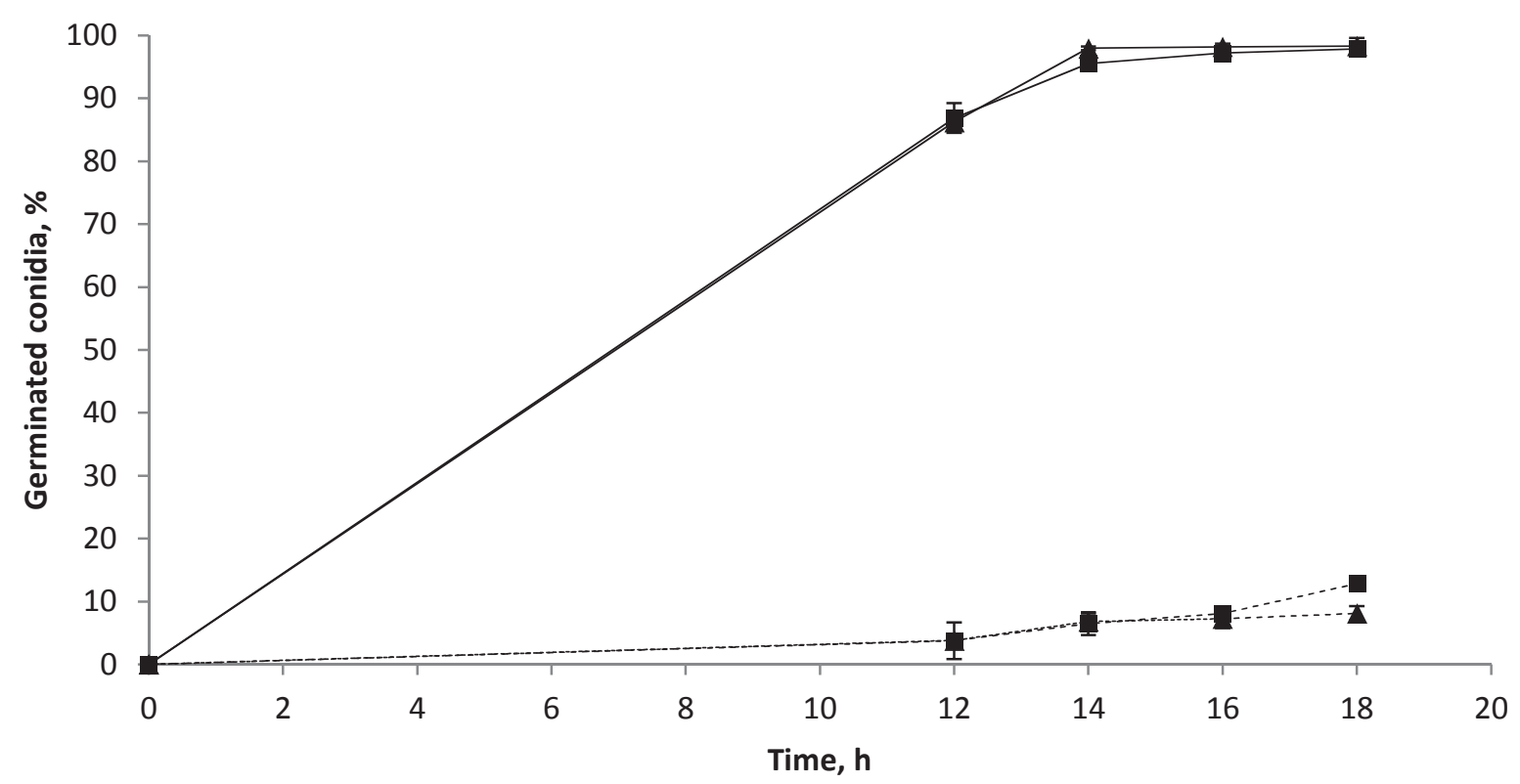

449

$450 \quad$ Fig. 3.

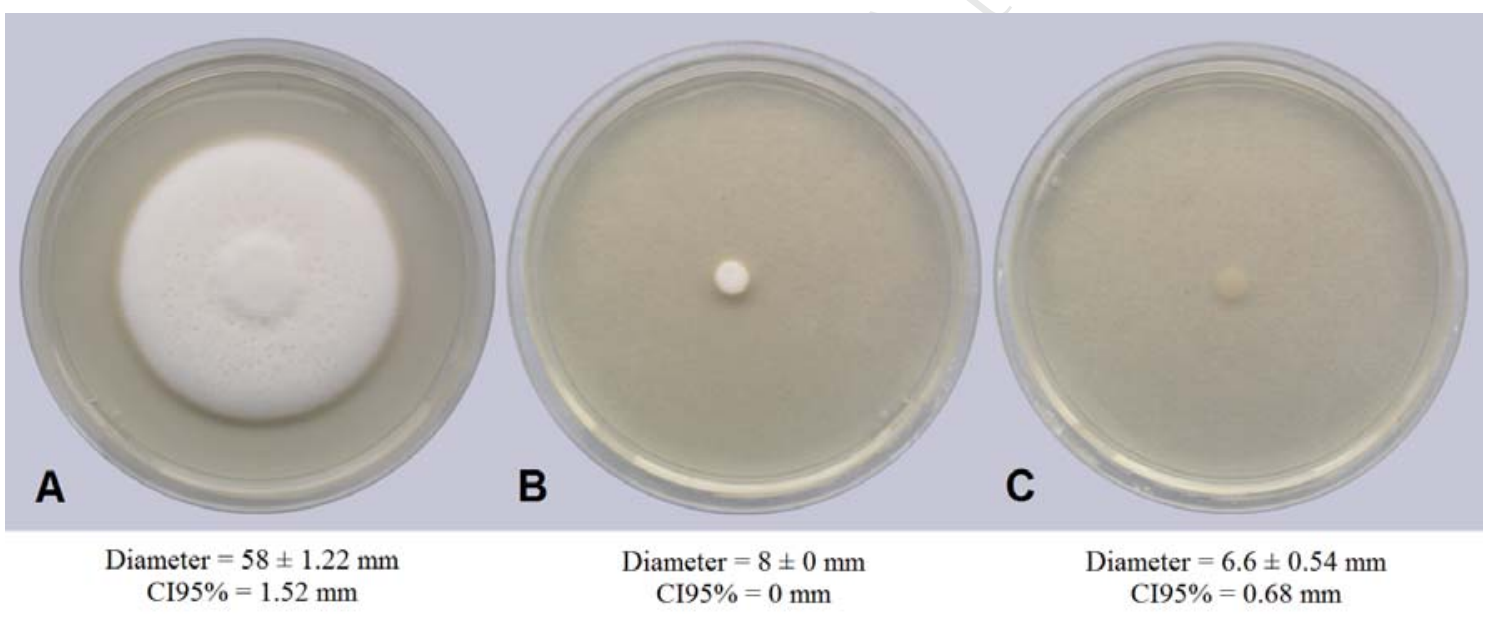

451

CI95\% $=1.52 \mathrm{~mm}$

CI $95 \%=0 \mathrm{~mm}$

$\mathrm{C} 195 \%=0.68 \mathrm{~mm}$ 
Fig. 4.
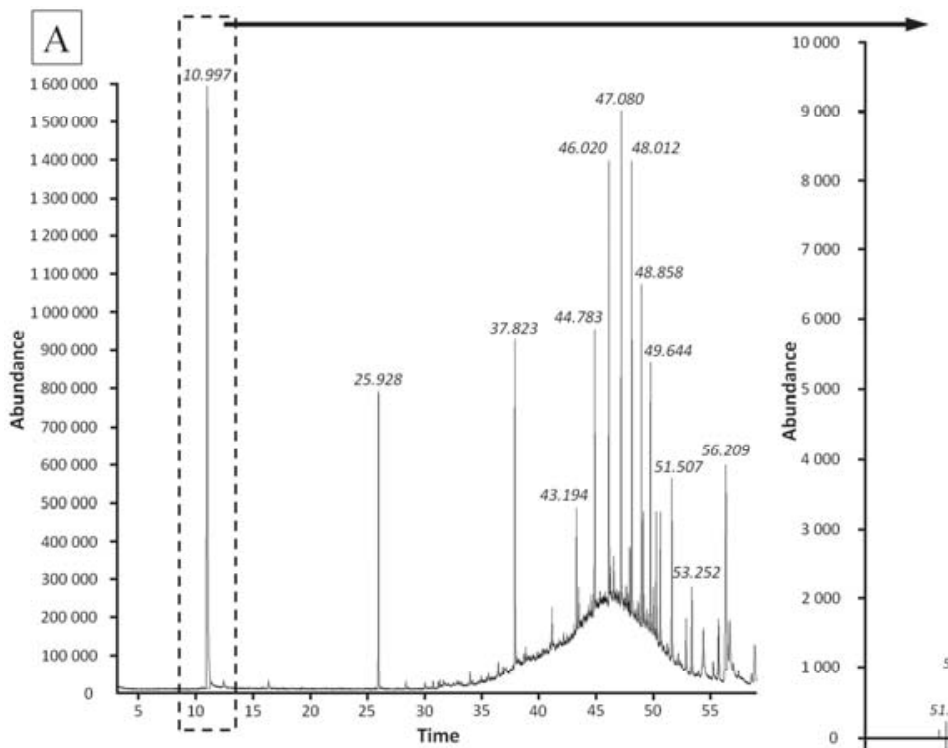

C
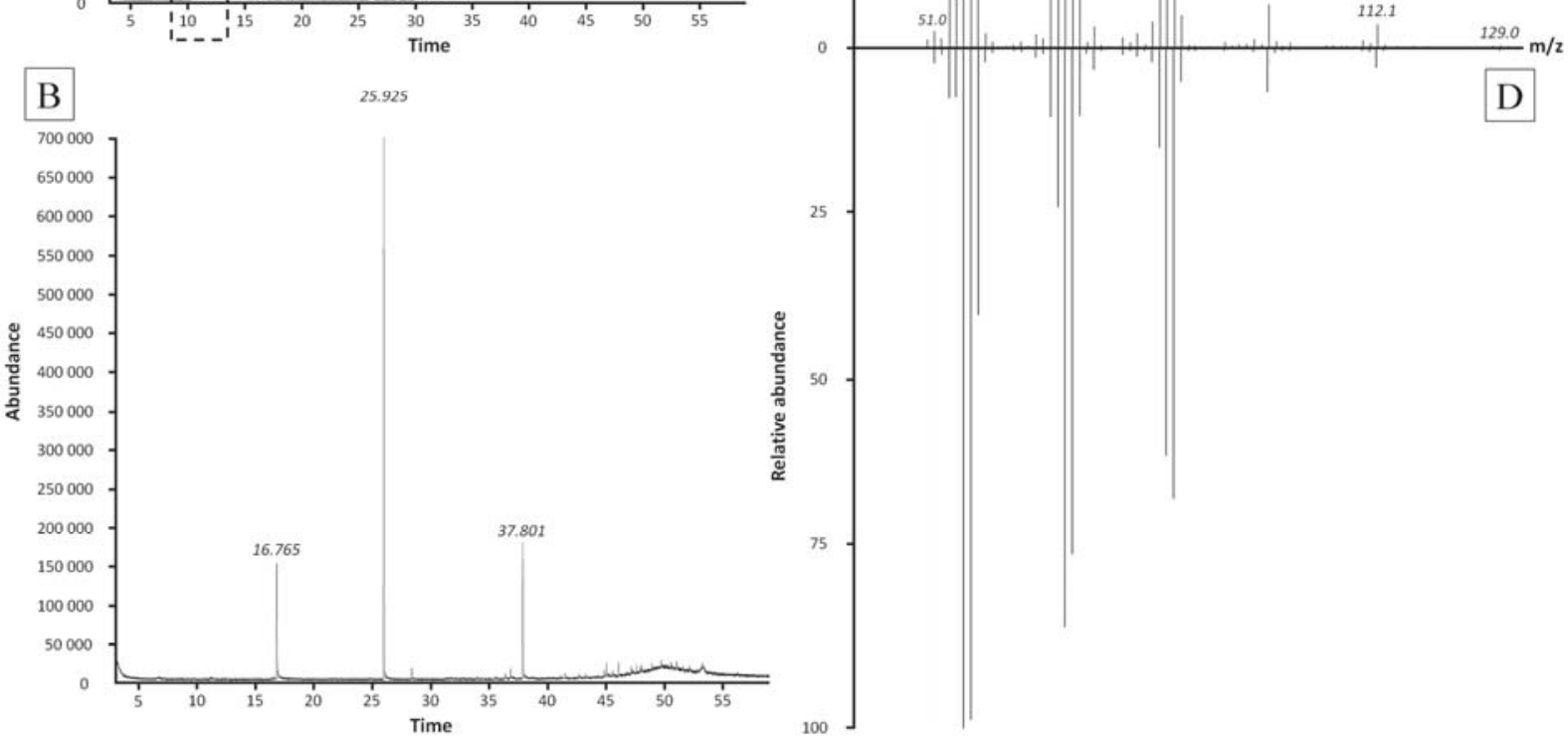

454

455

456

457

458

459

460

461

462

463 
Fig. 5.

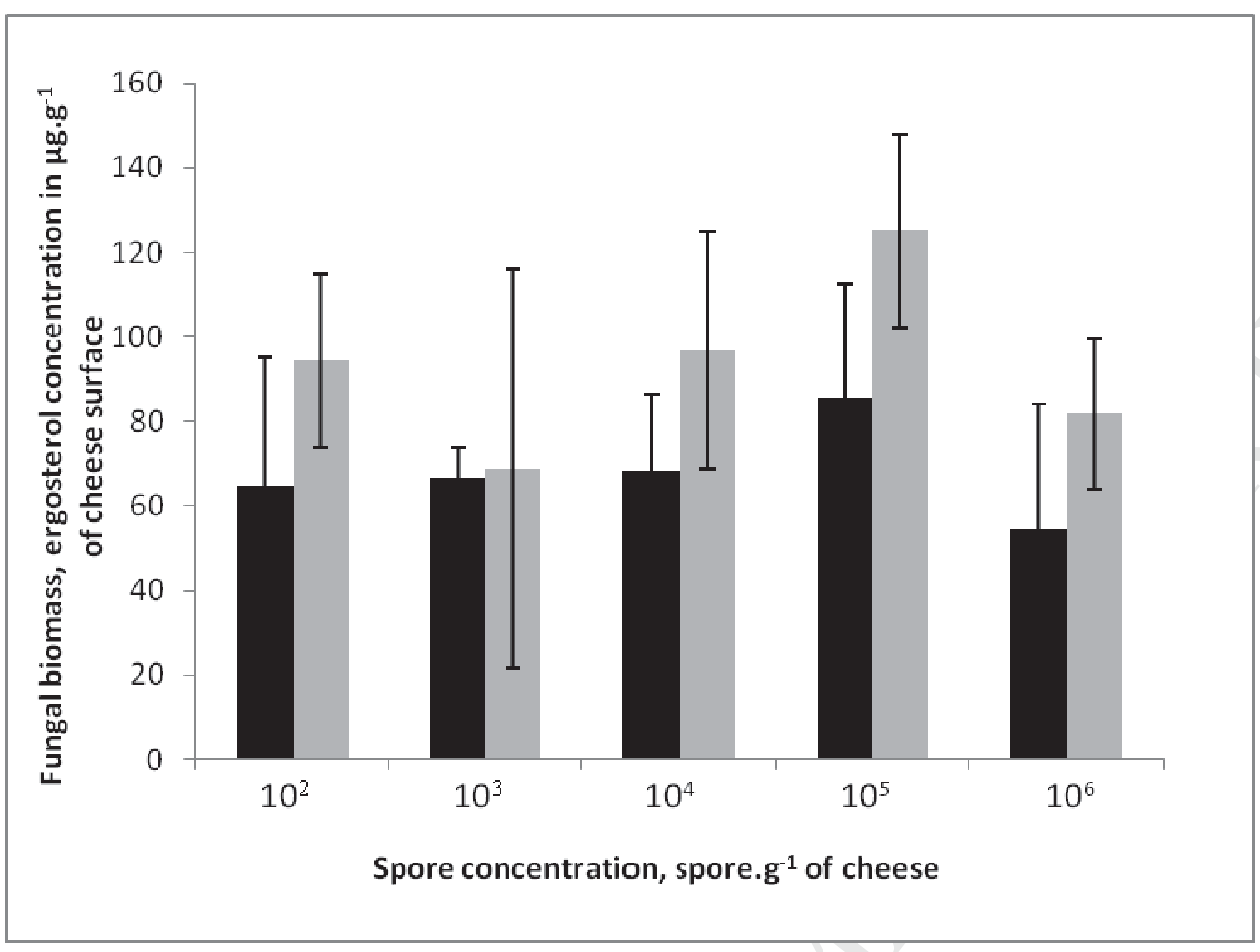




\section{Highlights:}

- Spore germination in Penicillium camemberti is self-regulated by quorum sensing.

- Quorum sensing is observed when spore densities are high.

- Compounds involved in quorum sensing are volatile.

- 1-octanol was found to be the main volatile compound produced at high-spore density. 